\title{
IS / IT Strategic Planning of Muhammadiyah 10 GKB Senior High School
}

\author{
Febryan Alandiestya Arif* \\ Faculty of Business and Technology Management \\ Institut Teknologi Sepuluh Nopember Surabaya (ITS) \\ Surabaya, Indonesia \\ *febreealandiestya@gmail.com
}

\begin{abstract}
In line with what was stated by the Southern Connecticut University that the making of strategic plans in any form is a significant effort. Whereas to strategically manage Information and Information Technology (IS / IT) Systems, understanding is needed on how the role of technology-based information systems has evolved in organizations. Moreover, the development of technology in these days has been so rapidly moving. Through this paper, the researcher aims to make an IS / IT strategic plan in an educational institution. This research will begin by compiling the Critical Success Factors, then executing the Gap Analysis to get comparisons between the actual conditions and the desired conditions. Next, the researcher will carry out the planning framework steps initiated by a firm named BerryDunn. This planning framework is commonly used by that firm in several institutions in the world and is expected to fill the gaps that might be found. The researcher hopes that this research can produce strategic IS / IT planning at Muhammadiyah 10 GKB Senior High School. In addition, this research is also expected to be able to provide benefits to the educational institutions in Indonesia.
\end{abstract}

Keywords: strategic planning, IS / IT, Critical Success Factors, Gap Analysis, BerryDunn's planning framework, Senior High School

\section{INTRODUCTION}

As time goes by, an organization can carry out a productive strategic planning process, so that leadership within the organization will be clarified as well as emphasizing the mission and values of the organization, in order to be able to define its role in society. This process can also identify external and internal challenges and opportunities that might be met to help design strategies that might be faced by the organization in order to design a very well-thought strategy [1]. An organization will face times of uncertainty. Therefore, managers need a mechanism, procedure, methodology to monitor and react to the surrounding environment. Strategic planning is that methodology. It is important to remember that strategic planning is a process, not a product. Strategic planning like this must be ongoing and permanent. This determines the final goal to be achieved and how the strategy to access it, allocate it, and manage its resources to achieve the goals that have been determined [2].

To manage Information Systems and Information Technology (IS / IT) strategically, it requires an understanding of how the role of technology-based information systems that have now evolved in organizations [3]. The things that are commonly found today are the spread of information through internet networks such as websites, WhatsApp, Instagram and others. In addition to information that is spread through the internet, we need to know that IT refers specifically to technology, basically hardware, software and telecommunications networks. Thus, there are so-called tangible / tangible (for example by servers, PCs, routers and network cables) and intangible / intangibles (for example with software of all types). Thus, the use of IT will be to facilitate the acquisition, processing, storage, transmission and sharing of information and other digital content [3].

The use of Information Technology as it can already be felt in various places, especially in an educational institution called Muhammadiyah 10 GKB Senior High School which was founded on January 22, year 2015. Muhammadiyah 10 GKB Gresik Senior High School (hereinafter referred to: SMAMIO) stands on an area of 9,675 square meters with complete facilities, supporting facilities and learning infrastructure [4]. Through its official Facebook account, the school carries the motto "Excellent with Character Education", which SMAMIO continues to strive to design learning that is oriented towards innovative, creative, enjoy and fun learning. In addition, SMAMIO has been supported by well-known university graduates who are competent in their fields, young, enthusiastic, creative, and have a vision and mission that is in line with Muhammadiyah's educational curriculum, namely by aligning academic education with Islamic education. The following are some of the facilities that can be enjoyed inside the school:

A spacious and comfortable mosque;

- Representative classrooms;

- Physics, chemistry, biology, IT, banking, entrepreneur \& trading laboratories;

- Comfortable library with a complete book collection;

- Basketball court and other sports facilities; and

- Very large yard, safe vehicle parking \& hygienic canteen. 
In addition, some posters were scattered within the school area that showed the school's vision and mission to be read and practiced every day. Related to the vision \& mission of the school, the researcher then held discussions with the Principal along with all the existing Vice Principals so as to obtain several important points that were referred to as the organizational goals of SMAMIO, including:

- Able to obtain a significant increase in the number of new students who enter each year;

- Able to obtain a significant increase in the number of final-year students who will enter well-known tertiary institutions each year;

- Able to improve and develop the use of technology and information within the school environment.

Starting from the vision \& mission along with the objectives of the organization, the researcher intends to utilize some methods and tools which will be able to find gaps that might exist between present and expected conditions. In the final part, a particular planning framework will strengthen the results of this research.

In the context of a business organization, CSF illustrates the principles that underlie or guide the efforts that must be considered to ensure that it is successful [5]. There should be differences when considering CSF as a strategic driver at the organizational level, or even at the company level. Therefore, CSF is more than just a guiding principle; rather, they are considered as an important component of the strategic plan that must be achieved besides the goals and objectives of the organization. Although this difference is not very visible, it is intended to show that organizational CSF is not only kept in mind but must be executed successfully in order to encourage the organization to achieve its mission [5].

There are two sources that are considered very important by Caralli also Ward and Peppard, namely internal and external CSF. Internal CSF is the things that are in the control range for certain managers. In contrast, external CSF is where managers have little control. For example, in the example of the aviation industry, internal CSFs can manage ground operations, while external CSFs may represent fuel costs. In fact, a researcher from Iran also stated that internal CSF will be pitted with an external CSF. This means that the internal CSF is connected to the manager or staff of the individual he / she controls, for example, the CSF is connected to the subject and conditions in managerial governance. External CSF is most often outside the administrative effect, for example is like the need for raw materials [6].

Categorizing CSF as internal or external is important because it can provide better insights for managers in setting goals [5]. For example, a manager can set very specific and attainable goals that complement internal CSF achievements because the manager has control over them. However, if a manager has an external CSF, he must set goals that aim to achieve CSF and minimize the impact on operations that might occur because CSF is not in direct control.

A document published by the Department of Agriculture and Food of Western Australia Government inspires the researcher to understand and implement the CSF along with its Key Performance Indicators. The following table is used as an indispensable tool for implementing CSF:

TABLE I. CSF \& KPI IDENTIFICATION TABLE BY THE DEPARTMENT OF AGRICULTURE AND FOOD OF WESTERN AUSTRALIA GOVERNMENT

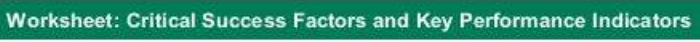

Goal:

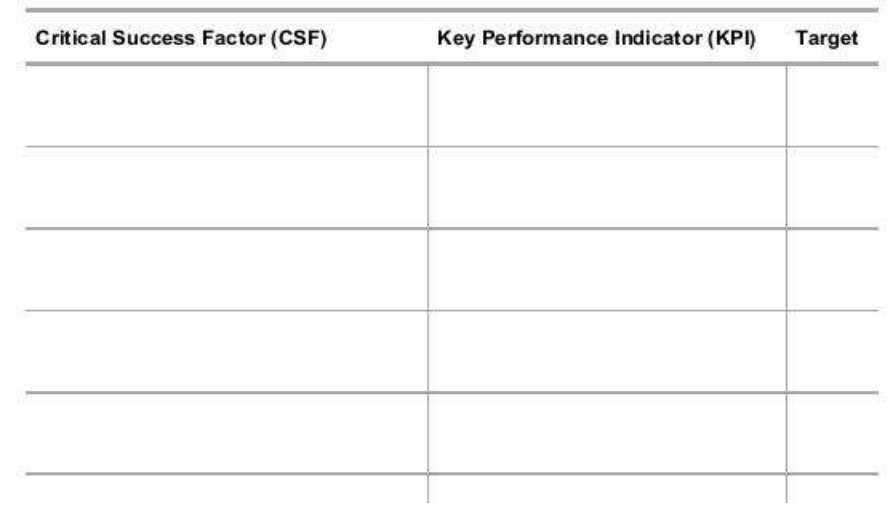

As according to Kaplan \& Norton quoted from the conference paper by Miroslav Hrnciar that the proper use of Gap Analysis will produce potential disclosures for improvement efforts, which are also present in their processes and interfaces. Thus, the aim is to fill the gaps that have been identified through reasonable steps. Gap Analysis is intended to create a management role in the process of implementing a management system that is related to achieving the organization's vision.

Miroslav Hrnciar argues that the identifiable gap is caused solely by the way the organization's management works. Any gaps that can be identified, indicate that management has a deficit in the success of organizational control and the organization has not fully utilized the existing potential. So, to make full use of this potential, an organization must carry out strategic planning.

Some electronic documents related to the application of IS / IT strategic planning are available on the internet and can be downloaded through Google search engines for free. Regarding this, the researcher managed to obtain documents with the object of an educational institution, for example at: Southern Connecticut State University, Saskatchewan University, Boston College, Elon University, College of Staten Island, University of Oxford, University of South Florida, to New South Wales Education. Some of the names of familiar educational institutions consider and try to prove that strategic planning is important for a certain period of time, most of which compile it within the next 5 years, so that these documents successfully bring the researcher into thinking that in arranging strategic planning in an educational institution is really important.

In line with what was mentioned by New South Wales Education in their introduction, that we now live in a digital 
age where students need new knowledge and new skills, in order to succeed in their lessons as well as in living their days in the present and the future. In order to face the digital era, students must think critically, solve problems creatively, work in teams, communicate clearly in various media and continue to learn new technologies so they can continue to develop. With this study, researchers became very interested to be involved in the preparation of strategic IS / IT at SMAMIO.

There are several electronic documents that are able to present ideas about a framework that can be used to develop IS / IT strategic planning such as the work of Wanwipa Titthasiri from Rangsit University. Wanwipa offered a proposal to the Thai government to help high-level institutions in formulating IS / IT strategic planning. However, what Wanwipa offers is something that is still less interactive, moreover there is still no evidence that institutions in the country have tried to do it. Therefore, this thesis researcher did not dare to follow the framework.

When the researcher reviewed the documents published by a firm named Berry, Dunn, McNeil \& Parker (BerryDunn) [7], this time the researcher was interested in the ideas and ways used by them. The firm, which has been established since 1974, has handled many private and state departments to make it easier for them to come up with a strategic plan. The resarcher is interested in the works of the firm because it looks very professional, proven and tested, and the end result is also interactive. All documents issued by this firm state that strategic planning needs to be prepared in a long process and requires human resources that are closely related to IT. From these documents, the researcher managed to obtain important things that made it possible to serve as a framework for conducting IS / IT strategic planning in an institution. In the document titled Town of Farragut's Information Technology Strategic Planning Project, there is a framework accompanied by discussion and steps they take to develop the plan. According to researcher, what they do can represent several important components in preparing IS / IT strategic planning. As a general description, here is the framework that was put forward by the firm:

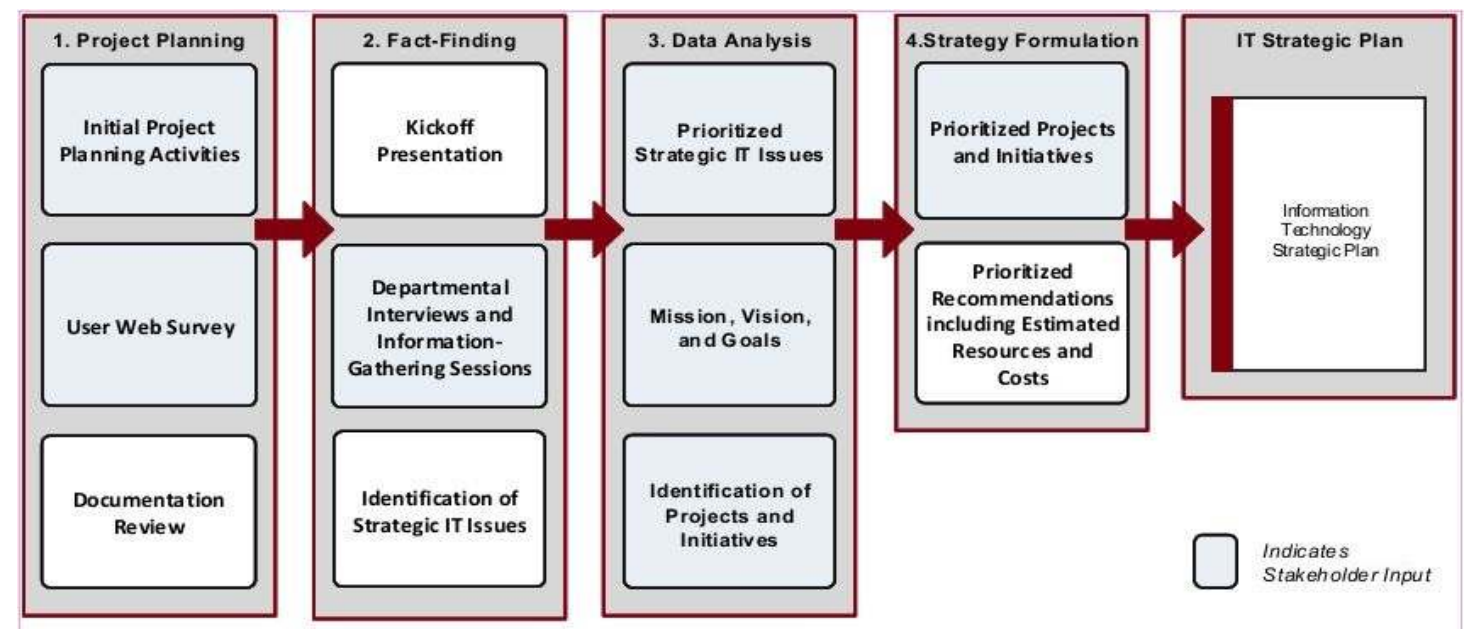

Fig. 1. BerryDunn's planning framework.

Based on the background that has been described, the researcher can formulate the problem as follows: "What is the strategic planning of the IS / IT that must be carried out by SMAMIO which are also in line with the objectives of the organization?". If the results of this study provide numbers of output in the form of strategic recommendations, the researcher will only present the points that are designated as "urgent" status.

\section{RESEARCH METHOD}

This research methodology is intended to facilitate researchers in understanding the concept design and research resources. Data collection in this study was carried out by conducting observation activities, such as interviews with the respondents. The respondents consisted of two groups. This first group is the company's stakeholders such as: 1 Principal, 1 Deputy Principal in marketing, 1 Deputy Principal in the public section, 1 Deputy Principal in the student section, 1 Deputy Principal in the curriculum section, and 1 Deputy Principal of the ISMUBA section. While the second group is consisted of members / subordinates of each section / division, as many as 2 people in each section / division. The data processing method is as follows:

\section{A. Doing the Analysis of Critical Success Factors}

The first phase is to identify Critical Success Factors (CSF) that can be obtained by completing interviews with stakeholders in the school. The identification of CSF is emphasized in 5 divisions that exist in schools, both those that relate internally or externally. The CSF was later identified using the CSF \& KPI Identification Tables which were inspired by the Department of Agriculture and Food of Western Australia Government. Then in the next stage, the results of the CSF identification are useful to identify the challenges that might be faced by the school. That way, this CSF can help the school and researchers as the earliest stage in preparing strategic planning in the school. 


\section{B. Doing the Gap Analysis}

The next phase is to carry out a Gap Analysis that might appear in the management environment of SMAMIO by conducting interviews with stakeholders in the school. In addition, observations in the field are also carried out by researchers in order to discover the reality that is happening in the field. This Gap Analysis is emphasized based on the information from the 7 gaps in the chapter 2 theory explanation. The findings of the gaps become a very important note and are used as a reference in implementing the BerryDunn's planning framework in the later stages. That way, this Gap Analysis aims to see the current conditions, but faced with expectations that are in accordance with business goals (organizational goals). The following is a gap analysis table used as a media to identify whether or not the gap is meant:

TABLE II. TRADITIONAL GAP ANALYISIS \& RESOLUTION MATRIX

\begin{tabular}{|l|l|l|c|c|c|c|}
\hline No. & Vision & Mission & $\begin{array}{c}\text { Existing } \\
\text { Condition }\end{array}$ & $\begin{array}{c}\text { Expected } \\
\text { Condition }\end{array}$ & $\begin{array}{c}\text { The } \\
\text { Gaps }\end{array}$ & $\begin{array}{c}\text { Resolu- } \\
\text { tion }\end{array}$ \\
\hline & & & & & & \\
\hline
\end{tabular}

\section{The Creation of Strategic Planning by Using BerryDunn's Planning Framework}

1) Project planning, At this stage of Project Planning, researcher did the interview with stakeholders because they must be able to find any initiatives that have been carried out by management so far (initial project planning activities) which are also checked according to table 2 . In addition, there are also online web-based surveys, which are online polls and are also used as reference material in simple identification of challenges. All of which aims to get a general picture of the current state of technology such as infrastructure, hardware, software, trends, and related support teams. The interview was conducted by researcher to:

- School Principal;

- Deputy Principal of public section;

- Deputy Principal of student section;

- Deputy Principal of curriculum section; and

- Deputy Principal of ISMUBA.

Next is the implementation of a review of the interview and also the online web-based survey in order to understand the current state of the SMAMIO, and what it will face in the future. With this, the researcher hopes to get points that contain several issues and opportunities for each department, which are then put into 3 functional aspects as done by the BerryDunn firm. The following are what are referred to as 3 functional areas, they are:

2) Management \& operational (code 'O'), Relating to how the management provides financial support, its management, planning and allocation.

3) Application (code ' $A$ '), In connection with its application in the field in order to support the company's main business activities.
4) Technical (code ' $T$ '), Relating to the development and maintenance of the technology used.

The results of the Project Planning stage are called the Preliminary List which will be used as an important document by each department in the school. At the end, this document can be referred to as "Department Priority", because it is the result of the thoughts and discussions of the heads of departments in the school together with the researcher.

5) Fact finding, After being able to produce a Preliminary List, the researcher begins to include members or subordinates of each stakeholder. This discussion discusses which points are considered as priorities to be done immediately, and which ones are considered not too priority. Each department is required to invite two members / subordinates so that the results obtained can be sharper. In total, there were 15 respondents who were summoned to attend this meeting and held in the internal boardroom of SMAMIO. What needs to be done is to do a weighting of each point in the Department Priority. Each respondent is entitled and must provide a score in accordance with the following guidelines:

TABLE III. PRIORITY KEYS (PRIORITIZATION GUIDELINES)

\begin{tabular}{|l|l|l|}
\hline Score & \multicolumn{1}{|c|}{ Status } & \multicolumn{1}{c|}{ Description } \\
\hline 3 & Critical & Must be handled from the first year \\
\hline 2 & High & Must be handled from the second or third year \\
\hline 1 & Medium & Must be handled from the fourth or fifth year \\
\hline
\end{tabular}

Respondents only need to give points 1 , or 2 , or 3 according to their own thoughts based on their experience in the field. At the end of the discussion, the researcher got the result that the issue and opportunity with the highest score were the most prioritized. Immediately after that, the researcher is obliged to make a list that is sorted based on the total value per point. In this case, the statement with the highest score is automatically ranked top. Henceforth, this document is referred to as the Strategic Issue \& Opportunity Rank.

6) Data analysis, In the Data Analysis stage, the researcher first reflects on the priority scoring results faced with the school's vision and mission so as not to overdo it. The reflection also needs to be emphasized on business goals that may already exist and are announced by the company. So, the respondents can still sort and revise the priority scoring. Whether or not there is a revision depends on the vision and mission of each company. After reflection, the next step is to weight the points of the revised Strategic Issue \& Opportunity Rank (if revision is needed). In this section, the researcher take part in giving priority to these points. Here is the division: 


\section{Weighted Prioritization Categories}

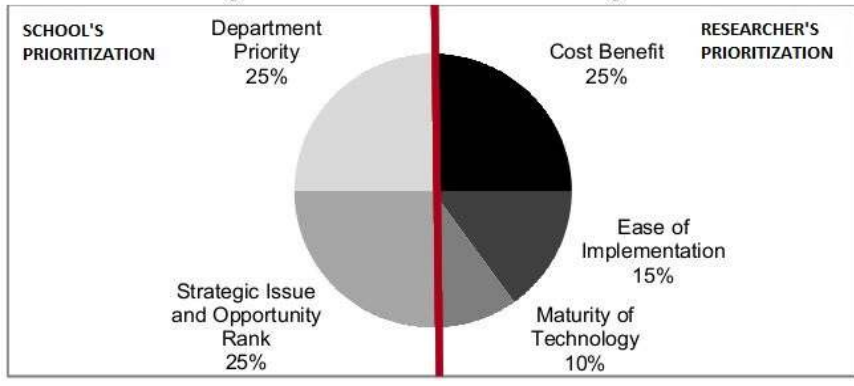

Fig. 2. Distribution Allocation Diagram.

In essence, the school has the authority to sort and assess existing issues, while researchers have the authority to assess the cost benefits, ease of implementation \& maturity of technology. This must be mutually agreed, that adding business value by utilizing IT / IS is not by reducing the company's cost burden [3]. The weighting must be entered directly in accordance with the order in the Strategic Issue \& Opportunity Rank. The following is a display of weighting according to a BerryDunn firm's template:

\begin{tabular}{|c|c|c|c|c|}
\hline \multicolumn{5}{|c|}{ Strategic Initiatives Weighted Prioritization Categories } \\
\hline \multicolumn{2}{|c|}{ SCHOOL } & \multicolumn{3}{|c|}{ RESEARCHER } \\
\hline $\begin{array}{l}\text { Strategic Issue and } \\
\text { Opportunity Rank }\end{array}$ & $\begin{array}{l}\text { Department } \\
\text { Priority }\end{array}$ & Cost Benefit & $\begin{array}{c}\text { Ease of } \\
\text { Implementation }\end{array}$ & $\begin{array}{l}\text { Maturity of } \\
\text { Technology }\end{array}$ \\
\hline $25 \%$ & $25 \%$ & $25 \%$ & $15 \%$ & $10 \%$ \\
\hline Critical & Critical & High & Easy & Established \\
\hline High & High & Medium & Medium & Leading Edge \\
\hline Medium & Medium & Low & Difflicult & Bleeding Edge \\
\hline
\end{tabular}

Fig. 3. Weighting the analysis results of each strategy.

7) Strategy formulation, At this Strategy Formulation stage, the researcher immediately merges the results of the previous stages into a template owned by the BerryDunn firm, as in Figure 4 below:

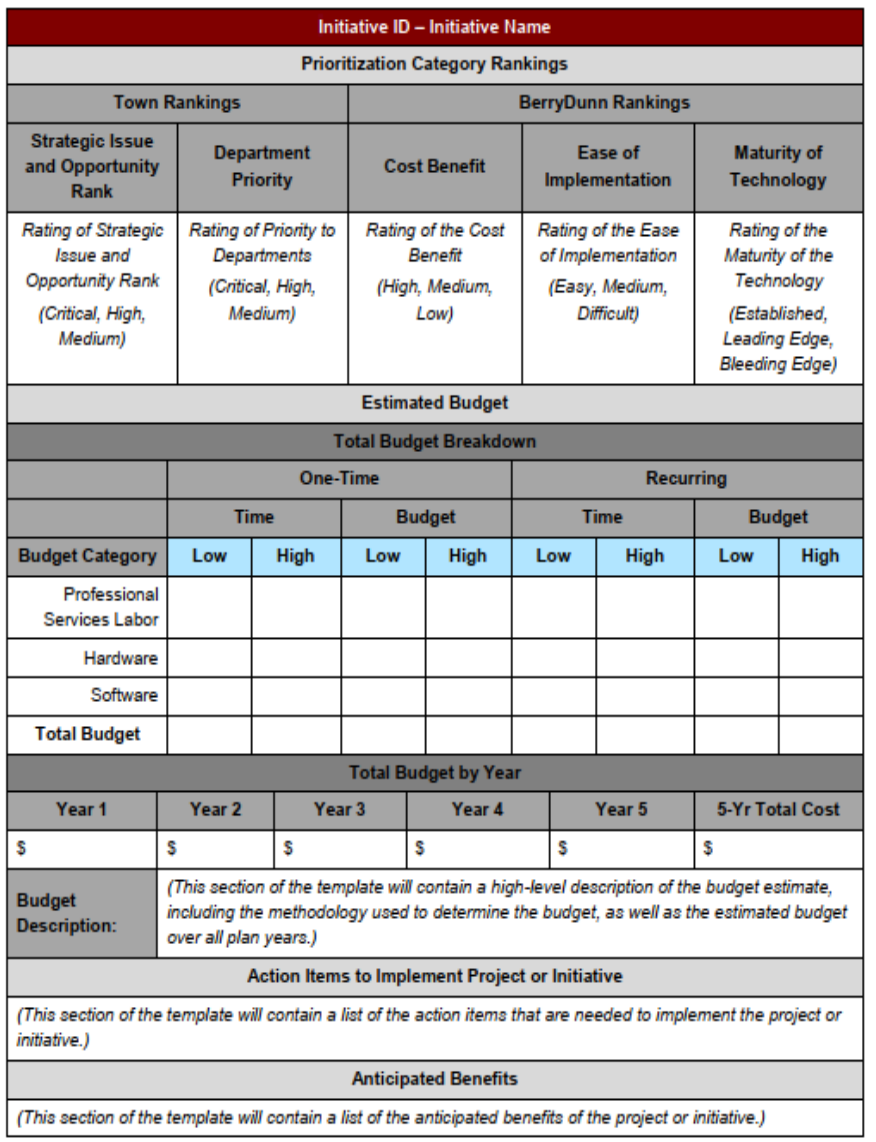

Fig. 4. The strategy template.

\section{RESEARCH RESULTS}

\section{A. $\quad$ The Result of Critical Success Factors}

From the first step (CSF), there are some internal \& external factors which influence the success of organizational goals.

1) The 1st goal: "Achieving a significant escalation in the amount of new-year student"

$$
\begin{aligned}
& \Rightarrow \quad 3 \text { internal factors } \\
& \Rightarrow \quad 3 \text { external factors } \\
& \text { (6 factors in total) }
\end{aligned}
$$

2) The 2nd goal: "Achieving a significant escalation in the amount of the graduated students who get through into famous universities"

$$
\begin{aligned}
& \Rightarrow \quad 4 \text { internal factors } \\
& \Rightarrow \quad 2 \text { external factors } \\
& \text { (6 factors in total) }
\end{aligned}
$$

3) The 3rd goal: "Escalating \& expanding the use of Information \& Technology inside the school area"

$$
\begin{aligned}
& \Rightarrow \quad 6 \text { internal factors } \\
& \Rightarrow \quad 5 \text { external factors } \\
& \text { (11 factors in total) }
\end{aligned}
$$




\section{B. The Result of Gap Analysis}

From the second step (Gap Analysis), there are 16 gaps that were found. Here is the elaboration related to each school's mission:

- 3 gaps found related to the $1^{\text {st }}$ mission ("Escalating \& implementing the Islamic education which based on the Quran and Sunnah, comprehensively")

- 2 gaps found related to the $2^{\text {nd }}$ mission ("Deriving a faithful academic, noble, independent \& responsible character in practicing the scientific knowledge for their daily life")

- 11 gaps found related to the $3^{\text {rd }}$ mission ("Actively participate in developing the common education field for Muhammadiyah and its surroundings")

\section{The Result of BerryDunn's Planning Framework}

1) Preliminary list, In this Initial Project Planning, the items are taken from 16 gaps in the early process from the Gap Analysis' result above.

2) Departmental priority, In this step, the researcher and the stakeholders give the code of each item taken from Preliminary List. Then, this document is called the Strategic Issue \& Opportunity. Here is the elaboration:

- There are 2 items for the Management \& Operational scope (M1 \& M2);

- There are 5 items for the Application scope (A1, A2, A3, A4, A5); and

- There are 9 items for the Technical scope (T1, T2, T3, T4, T5, T6, T7, T8, T9).

3) Fact finding, After all of the Preliminary List items are coded, them the researcher, stakeholders, and selected respondents were discussing the prioritizing (ranking) of each Strategic Issue \& Opportunity above. Here is the elaboration:

- There are 3 items designated as "critical" (M1, M2, \& T9)

- There are 5 items designated as "high" (A3, T2, A1, $\mathrm{T} 7, \mathrm{~T} 6)$

- There are 8 items designated as "medium" (T8, T3, A2, T5, A5, T4, A4, T1)

4) Data analysis, In this step, the researcher is weighing every single prioritized strategic issue \& opportunity above with the wisdom and the surroundings observation. So, this weighing cannot be interrupted or influenced by the stakeholders or the other elements of this school.

5) Strategy formulation, All of the documented actions are merged into a comprehensive template, which then can be considered as the portfolio. In this action, every single prioritized (ranked) category should be added by other suggestions, such as:

- Initiative description

- Initiative source information

- Estimated budget

- Estimated budget by year

- Action items of implementation

- Anticipated benefits

\section{The Portfolio (The Strategic Planning)}

This part is the section where all of the documented actions are merged into a comprehensive template, including the 6 suggestions as mentioned above. Due to the limitation of this study, the researcher only shows the Strategic Plan which are considered as "critical" (M1, M2, \& T9). Here is the look of the strategic planning portfolio:

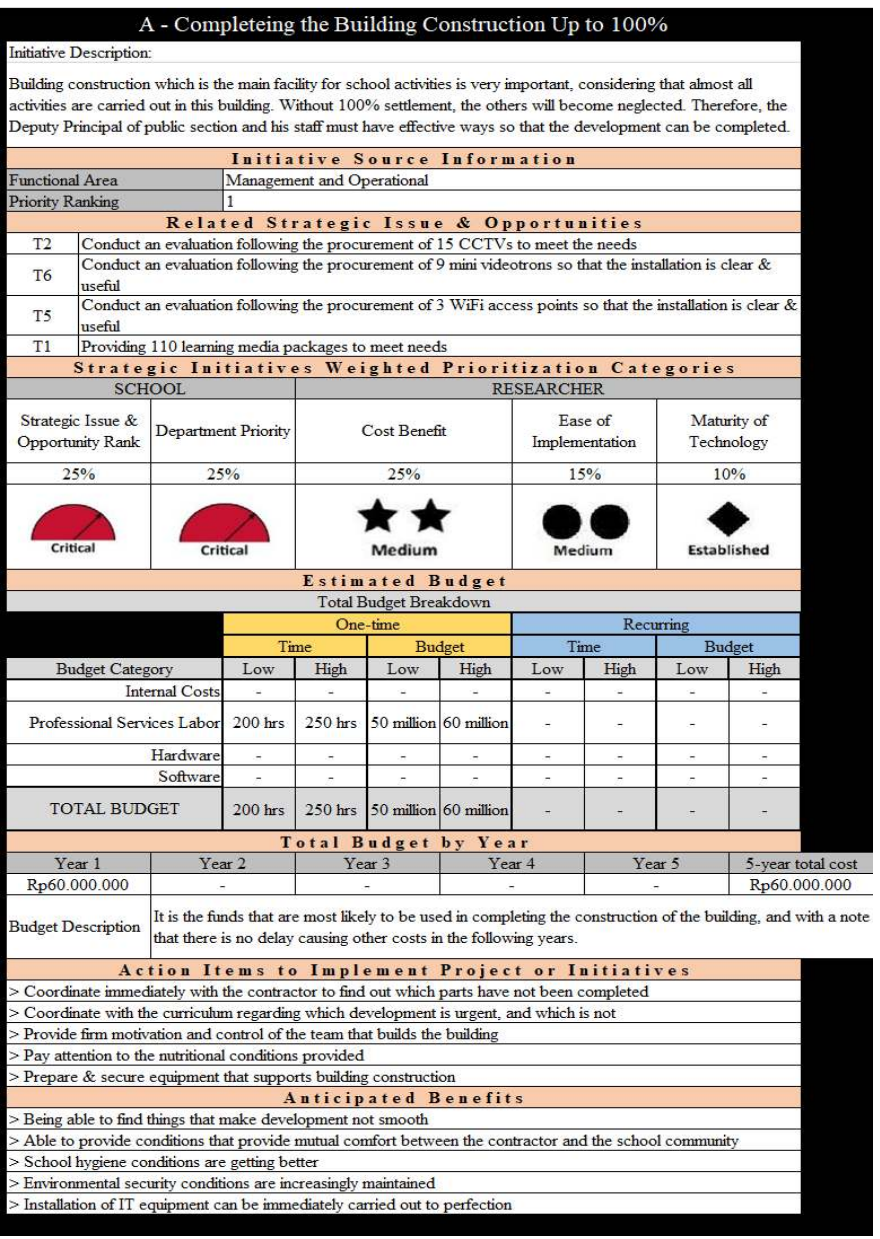

Fig. 5. Strategy portfolio A. 


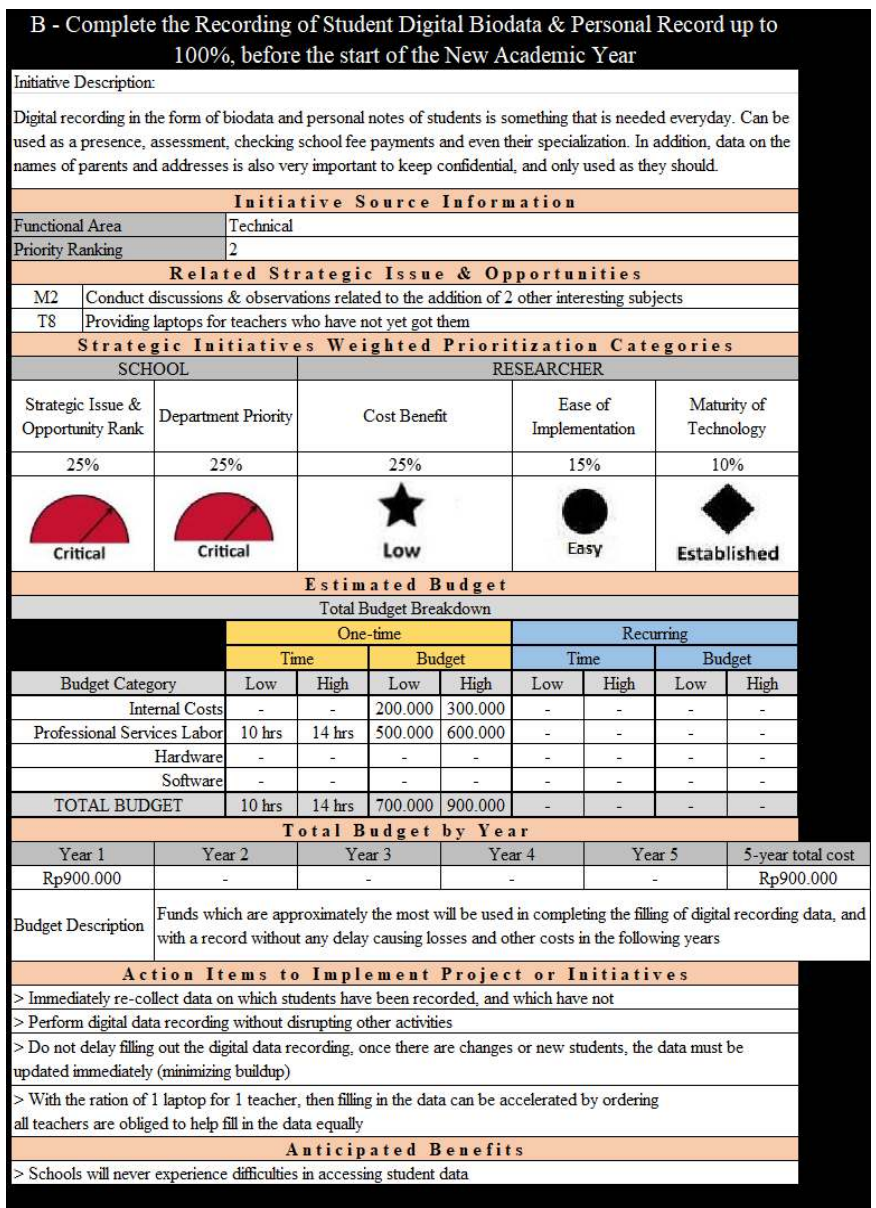

Fig. 6. Strategy portfolio B.

\section{CONCLUSION}

Strategic planning in the IT / IS field is very important. However, in planning strategic matters in the IT / IS field it must be aligned with business / organizational goals, and also still be reflected in its vision \& mission. Looking at the results of the research (strategy portfolio A, B and C), the real purpose of IT / SI strategic planning is not to save money. This is also similar to that expressed by Ward \& Peppard. As also presented in the portfolio, IT / IS strategic planning is not a lifetime plan. There must be a time period, because IT / IS continues to grow rapidly. For this reason, strategy development must be limited by the timeframe of its implementation, so that there will be improvements as well as further planning in the future.

\section{REFERENCES}

[1] The Enterprise Foundation. 1999. Effective strategic planning. (Online). USA: Maryland. (http://my2.ewb.ca/site media/static/library/files/403/the-enterprisefoundation-effective-strategic-planning.pdf, accessed on 23 October 2018)

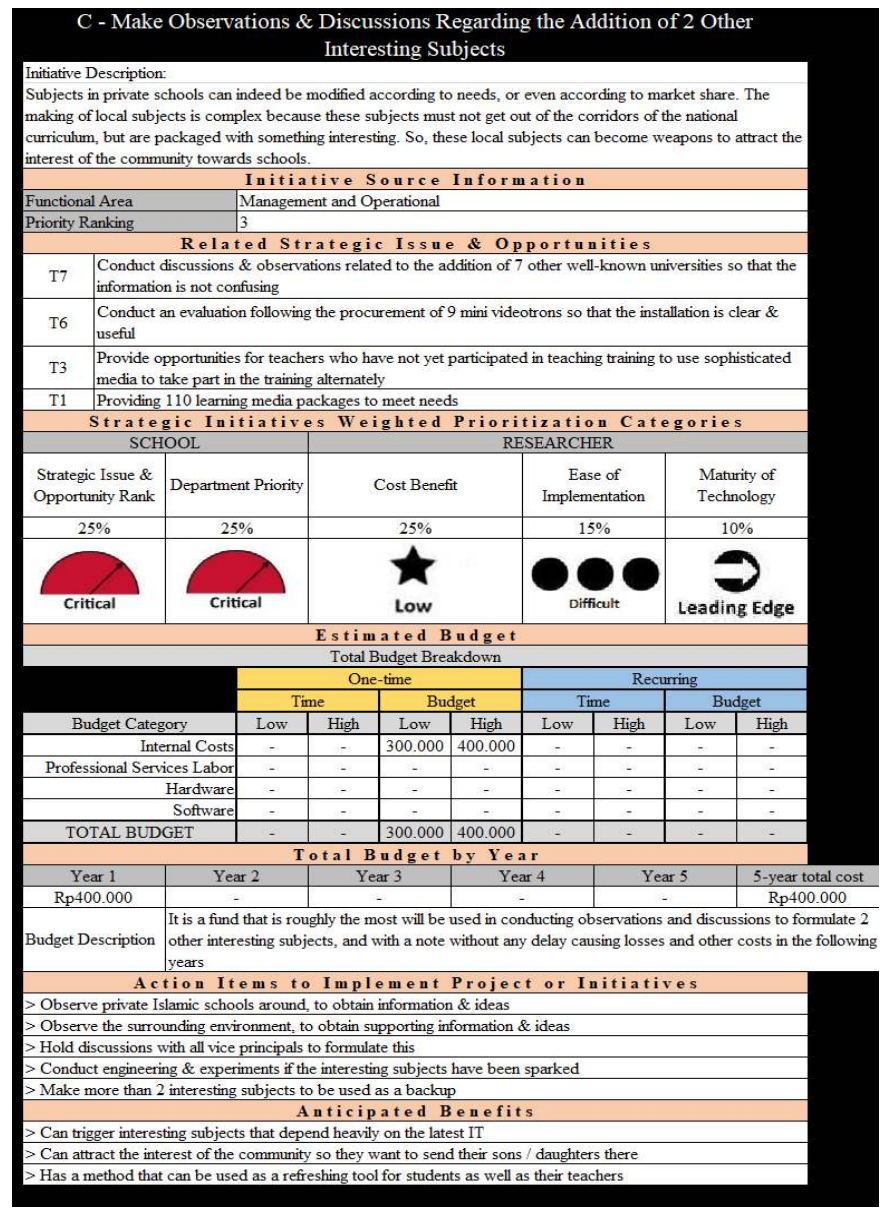

Fig. 7. Strategy portfolio C.

[2] Rezvani, Mousa, et al. 2011. Strategic planning: A tool for managing organizations in competitive environments. (Online). Australian Journal of Basic and Applied Sciences. Iran: Islamic Azar University Asara. (https://pdfs.semanticscholar.org/e5b6/a28d703e9a2e2214bcc601 cabf06 58e85791.pdf, accessed on 18 October 2018)

[3] Ward, John and Peppard, Joe. 2002. Strategic Planning for Information Systems. Third Edition. England: Jonh Wiley \& Sons, ltd.

[4] BLP Property. "Tentang kami". (http://blp-property.com/?page_id=13, accessed on 23 December 2018)

[5] Caralli, Richard A. 2004. The critical success factor method: Establishing a foundation for enterprise security management. (Online). Pittsburgh: Carnegie Mellon Software Engineering Institute. (https://apps.dtic.mil/dtic/tr/fulltext/u2/a443742.pdf, accessed on 24 October 2018))

[6] Rad, Samira S. 2015. Critical success factors (CSFs) in strategic planning of information systems. (Online). Accepted Journal of Applied Environmental and Biological Sciences. Iran: Islamic Azad University. (https://pdfs.semanticscholar.org/2292/d71ae700b8c90e9488e34a70783 159f2cee7.pdf, accessed on 20 October 2018)

[7] BerryDunn. 2016. Town of Farragut information technology strategic planning project. (Online). USA. (https://www.townoffarragut.org/DocumentCenter/View/3023/FarragutIT-Strategic-Plan-Final-Version-May-31-2016, accessed on 18 October 2018) 